Conclusions Here using an efficient strategy to express recombinant monoclonal antibodies from single B cells we demonstrated an elevated frequency of autoreactive naïve $B$ cells in the circulation of SS patients supporting the existence of early defects in B cell tolerance checkpoints in SS.

\section{A5.3 ALTERATIONS ON PERIPHERAL BLOOD B CELL COMPARTMENTS IN SYSTEMIC LUPUS ERYTHEMATOSUS: RELEVANCE FOR MONITORING LUPUS ACTIVITY AND THERAPY}

doi:10.1136/annrheumdis-2013-203219.3

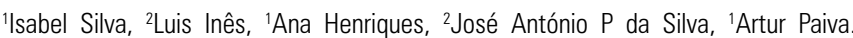
${ }^{1}$ Cytometry Service of the Blood and Transplantation Center of Coimbra, Portugal; ${ }^{2}$ Rheumatology Department; Centro Hospitalar e Universitário e Coimbra, Portugal

Background and Objectives Despite recent insights on abnormalities of blood B cell subsets in human systemic lupus erythematosus (SLE), a peripheral blood biomarker with useful clinical information about the occurrence of an active disease period hasn't yet been achieved. Moreover, the clinical relevance of anti-dsDNA antibodies and their utility for monitoring an individual patient remains a matter of debate. In this sense, we attempt to determine whether the degree of abnormalities of circulating B cell subsets correlates with SLE disease activity and constitute an useful tool for SLE patients monitoring.

Materials and Methods We analysed by flow cytometry the major circulating B cell subsets (immature, naïve, memory and plasmablast) and their expression profile of $B$ cell related molecules (CD19, CD20, CD81 and BAFFR) in 43 SLE patients, 18 with active and 25 with inactive disease, according to the SLE Disease Activity Index 2000 (SLEDAI, 2k), as well as in 30 healthy individuals.

Results The results pointed to the existence of significant alterations on B cell homeostasis that are significantly correlated with disease activity. An overall decrease in absolute numbers of all B cell subsets was observed in SLE patients, with the exception of IgGplasmablast that remained equal or even higher than in the control group, particularly in active disease. Additionally, a higher number of plasmablast expressing each Ig-heavy chain isotypes was found in patients with mucocutaneous involvement. Moreover, among memory B cells, an increased IgG and decreased IgM positive cellswas observed in both SLE groups.

Furthermore, a decreased expression of CD19 observed in active disease and an increased BAFFR expression in inactive disease in the majority of $B$ cell subsets, may contribute not only for breaking tolerance during $\mathrm{B}$ cell development, but also for enhancing plasmablast survival.

Conclusions In conclusion, flow cytometric monitoring of circulating B cell subsets, particularly focused on relative and absolute numbers of IgG plasmablasts, could provide a useful tool for monitoring disease activity, but also the therapy efficacy in patients with SLE.

\section{A5.4 ANTI CARBAMYLATED PROTEIN ANTIBODIES (ANTI-CARP) ARE PRESENT IN ARTHRALGIA PATIENTS AND PREDICT THE DEVELOPMENT OF RHEUMATOID ARTHRITIS}

doi:10.1136/annrheumdis-2013-203219.4

1,* Jing Shi, ${ }^{2, *}$ Lotte A van de Stadt, 'EW Nivine Levarht, 'Tom WJ Huizinga, 'René EM Toes, 'Leendert A Trouw, ${ }^{3}$ Dirkjan van Schaardenburg. 'Leiden University Medical Center, Leiden; '2Jan van Breemen Research Institute| Reade, Sanquin Research, Amsterdam; 3Jan van Breemen Research Institute | Reade and VU University Medical Center, Amsterdam, The Netherlands

*Mr. Shi and Dr. van de Stadt contributed equally to this work.

Background/Objective Recently, we discovered a new autoantibody system in rheumatoid arthritis (RA): anti carbamylated protein antibodies (anti-CarP). These antibodies have additional prognostic value in predicting joint destruction when compared to anti-citrullinated protein antibodies (ACPA). However, it is not yet known whether anti-CarP antibodies are present before the diagnosis of RA and whether they have predictive value for the development of RA. Therefore we studied whether anti-CarP antibodies are present in arthralgia patients and whether their presence associates with the development of RA.

Methods Sera of 340 arthralgia patients without clinical signs of arthritis and 32 healthy controls were measured for the presence of anti-CarP IgG antibodies. One hundred eleven arthralgia patients $(33 \%)$ were IgM-rheumatoid factor (IgM-RF) positive/anti-cyclic citrullinated peptide 2 (aCCP2) negative and 229 (67\%) were aCCP2 positive. Patients were followed for the development of RA (2010 criteria). The median follow up time was 36 months. Cox regression analysis was performed to compare the risk of developing RA between Anti-CarP positive and negative arthralgia patients in follow up time.

Results The arthralgia cohort consisted of 340 IgM-RF and/or aCCP positive patients. Anti-CarP antibodies were present in sera of $113(39 \%)$ of the tested patients. A total of 120 patients developed RA after a median (IOR) of 12 (6-24) months. The presence of antiCarP antibodies was associated with the development of RA in the whole arthralgia cohort even after correction for RF and aCCP2 status (HR: 1.56; 95\%CI: 1.06-2.29; $\mathrm{p}=0.023$ ), as well as in the aCCP2 positive subgroup (OR: 2.231; 95\%CI: 1.31-3.79; $p=0.003$ ).

Conclusions Anti-CarP antibodies were present in arthralgia patients and their presence predicted the development of RA independent of aCCP2 antibodies.

Disclosure These studies were financially supported by Janssen Biologics BV, (Johnson \& Johnson).

\section{A5.5 ANTIBODIES AGAINST DOMAIN I OF $\boldsymbol{\beta} 2$ GLYCOPROTEIN I IN ANTIPHOSPHOLIPID ANTIBODY SYNDROME}

doi:10.1136/annrheumdis-2013-203219.5

${ }^{1-3}$ Cecilia Chighizola, ${ }^{1}$ Francesca Pregnolato, 'Claudia Grossi, ${ }^{2,3}$ Maria Gerosa, ${ }^{4}$ Gary Norman, ${ }^{4}$ Michael Mahler, ${ }^{1,2}$ Maria Orietta Borghi, ${ }^{1-3}$ Pier Luigi Meroni. 'IRCCS Istituto Auxologico Italiano, Milan, Italy; ${ }^{2}$ University of Milan, Italy; ${ }^{3}$ stituto G Pini, Milan, Italy; ${ }^{4}$ Inova Diagnostics, Inc., San Diego, CA, USA

Background and Objectives antibodies anti-phospholipids (aPL) react to proteins bound to $\mathrm{PL}$, mainly $\beta 2$ glycoprotein I ( $\beta 2 \mathrm{GPI}$ ). Antibodies against $\beta 2 \mathrm{GPI}$ (a $\beta 2 \mathrm{GPI}$ ) exert a pathogenic role and represent a risk-factor for clinical manifestations of anti-phospholipid syndrome (APS). However, some aß2GPI-positive subjects never develop APS-related clinical manifestations. This observation may be explained by the heterogeneity of a $\beta 2 \mathrm{GPI}$ population, with autoantibody subgroups targeting different $\beta 2 \mathrm{GPI}$ epitopes. In particular, antibodies anti-domain I (aDI) but not domains IV and V $(\mathrm{aDIV} / \mathrm{V})$ of $\beta 2 \mathrm{GPI}$ have been associated with thrombotic events. Therefore, the aim of this study was to assess the prevalence of aDI and aDIV/V IgG in a cohort of aPL-positive patients.

Material and Methods 58 patients with a diagnosis of primary APS (PAPS) according to the 2006 Sydney criteria have been included in this study. 38 PAPS patients (65.5\%) presented with venous and/ or arterious thrombothic events while 20 subjects $(34.5 \%)$ had obstetric manifestations only. $15 \mathrm{aPL}$ asymptomatic carriers were also recruited. All samples had been tested for LA and for aCL and a 32 GPI with home-made assays according to international guidelines. In the thrombotic PAPS group, 35/38 subjects (92.1\%) were aß2GPI IgG positive; a 32 GPI IgG positivity rate was $85 \%$ in the obstetric PAPS group (17/20 women); $80 \%$ of the asymptomatic aPL carriers displayed a $\beta 2$ GPI IgG. IgG specificities against whole $\beta 2 \mathrm{GPI}$, $\mathrm{DI}$ and DIV/V have been evaluated with a novel solid-phase chemiluminiscent assay (BioFlash and ELISA, INOVA Diagnostics). 
Results Out of the 73 aPL positive patients:

- $21 \%$ were positive for a $32 \mathrm{GPI}, \mathrm{aDI}$ and $\mathrm{aDIV} / \mathrm{V}$

- $41 \%$ were positive for a $32 \mathrm{GPI}$ and aDI but negative for $\mathrm{aDIV} / \mathrm{V}$;

- $4 \%$ were positive for a 2 GPI and $\mathrm{aDIV} / \mathrm{V}$ but negative for $\mathrm{aDI}$;

- $21 \%$ were aß2GPI positive only;

- $4 \%$ were positive for aDIV/V;

- $9 \%$ were negative for antibodies against the whole molecule and the studied domains.

The prevalence of aDI was $74 \%$ among patients with thrombotic pAPS and $60 \%$ among women with obstetric manifestations. $40 \%$ of aPL asymptomatic carriers were positive for $\mathrm{aDI}$.

We observed a strong correlation between a $32 \mathrm{GPI}$ and $\mathrm{aDI}$ $(\mathrm{p}<<0.01, \mathrm{r}=0.836)$ but not aDIV/V $(\mathrm{p}=0.07, \mathrm{r}=0.216)$.

Conclusions Most of the a $32 \mathrm{GPI}$ positive sera displayed reactivity against DI, while aDIV/DV were detected in a low rate of patients. Our data suggest that DI is the immunodominant $\beta 2 \mathrm{GPI}$ epitope and that $\mathrm{aDI}$ are the main antibody population in APS patients. Future studies are warranted to better define the diagnostic and prognostic role of anti-DI in APS

\section{A5.6 ANTI-CARBAMYLATED PROTEIN ANTIBODIES ARE PRESENT IN MICE WITH COLLAGEN INDUCED ARTHRITIS}

doi:10.1136/annrheumdis-2013-203219.6

Jeroen Stoop, Bisheng Liu, Jing Shi, Diahann Jansen, Leendert Trouw, Rene Toes. Dept. of Rheumatology, Leiden University Medical Center, Leiden, The Netherlands

Objective Antibodies against citrullinated proteins (ACPA) are a characteristic of rheumatoid arthritis (RA). Carbamylation is a different type of post translational modification, where a Lysine amino acid is converted into a homocitrullin. Recently we identified antibodies binding to carbamylated proteins (anti-CarP) in a subgroup of RA patients. In ACPA negative RA patients anti-CarP antibodies associate with joint damage.

The Aim of this study was to determine whether these anti-CarP antibodies are present in animal models of arthritis.

Methods Collagen induced arthritis (CIA) was induced in DBA/1 $(\mathrm{n}=29)$ and $\mathrm{C} 57 \mathrm{Bl} / 6(\mathrm{n}=20)$ mice by immunisation with type II collagen in CFA. Arthritis severity was monitored using a clinical scoring system. Non-immunised animals $(n=9)$ served as negative controls. After disease onset serum was harvested and antibody levels were determined by ELISA. The specificity of our anti-CarP. ELISA was validated using dotblots.

Results Whereas no anti-CarP antibodies could be detected in nonimmunised DBA/1 mice, anti-CarP total Ig was present in $93 \%$ of the arthritic mice. Of those mice 39\% had IgG1 and 79\% had IgG2a anti-CarP antibodies. Antibodies to citrullinated proteins could not be detected. The levels of mouse collagen-specific IgG2a correlated with the clinical score. However, the levels of the different antiCarP isotypes did not. Around $60 \%$ of the immunised C56Bl/ 6 mice developed arthritis. Anti-CarP IgG2c could be detected in 55\% of those mice and could not be detected in the mice that did not get CIA. Anti-CarP IgG1 was detected in $28 \%$ of the arthritic mice. Interestingly, mouse collagen specific IgG2c antibodies were detected in $100 \%$ of the immunised C57Bl/ 6 mice. Dotblot analysis, using carbamylated and non-modified proteins confirmed the ELISA results regarding the specificity of the antibodies for homocitrulline containing proteins.

Conclusions Mice with CIA have antibodies to carbamylated proteins and their presence associated with disease development. All immunised mice have anti-mouse CII antibodies, indicating that the presence of anti-CarP antibodies could be a disease specific marker for arthritis in mice. Further studies will be required to determine the role of anti-CarP in the pathogenesis of arthritis.

\section{A5.7 AUTOANTIBODIES TO THE FIBRIN-DERIVED CITRULLINATED PEPTIDES $\alpha 36-50$ AND $\beta 60-74$ ARE TWO DISTINCT NON-OVERLAPPING SUBFAMILIES OF ACPA THAT TOGETHER ALMOST SUMMARISE THEIR REACTIVITY TO CITRULLINATED FIBRINOGEN AND TO CCP2 ANTIGENS}

doi:10.1136/annrheumdis-2013-203219.7

${ }^{1} \mathrm{M}$ Cornillet, ${ }^{1} \mathrm{M}$ Sebbag, ${ }^{2,3} \mathrm{E}$ Verrouil, ${ }^{4} \mathrm{~A}$ Magyar, ${ }^{2} \mathrm{~A}$ Ruyssen-Witrand, ${ }^{4} \mathrm{~F}$ Hudecz, ${ }^{2} \mathrm{~A}$ Cantagrel, ${ }^{1,3} \mathrm{G}$ Serre, ${ }^{1,3} \mathrm{~L}$ Nogueira. 'Laboratory of "Epidermis Differentiation and Rheumatoid Autoimmunity", UMR CNRS 5165, INSERM U 1056, Toulouse III University; ${ }^{2}$ Rheumatology Center, University Hospital of Toulouse; ${ }^{3}$ Laboratory of Cell Biology and Cytology, University Hospital of Toulouse; Toulouse, France; ${ }^{4}$ Research Group of Peptide Chemistry, Department of Organic Chemistry, Hungarian Academy of Sciences, Eötvös Loránd University, Budapest, Hungary

Objectives To evaluate the proportions of Rheumatoid Arthritis (RA) sera containing autoantibodies to citrullinated proteins (ACPA) reactive to $\alpha 36-50$ and/or $\beta 60-74$ two citrullinated peptides identified as bearing the immunodominant epitopes of their major target: citrullinated fibrin. To analyse the relationships of anti- $\alpha 36-50$ and anti- $\beta 60-74$ autoantibodies with autoantibodies to the whole citrullinated human fibrinogen (AhFibA) and with anti-CCP2 antibodies.

Methods 617 sera from 181 established RA and 436 non-RA rheumatic diseases were tested by ELISA for AhFibA, anti-CCP2, anti- $\alpha 36-50$, anti- $\beta 60-74$ autoantibodies, and by nephelometry for Rheumatoid Factor (RF). Diagnostic indexes, correlations and concordances between tests were analysed. Cross-reactivity between anti- $\alpha 36-50$ and anti- $\beta 60-74$ autoantibodies was analysed with peptide absorption experiments.

Results At diagnostic specificity of $95 \%$, the diagnostic sensitivity of AhFibA (83\%) was significantly higher than that of all other tests. The diagnostic sensitivity of anti- $\beta 60-74$ autoantibodies (71\%) was significantly higher than that of anti- $\alpha 36-50(51 \%)$ but similar to that of anti-CCP2 (74\%). Titres of RF, anti- $\alpha 36-50$ and anti- $\beta 60-74$ autoantibodies were weakly correlated with each other, whereas titres of anti- $\beta 60-74$ were strongly correlated with those of AhFibA (rho $=0.633$ ) and of anti-CCP2 (rho $=0.634)$. More than $90 \%$ of AhFibA-positive or anti-CCP2-positive sera recognised the $\alpha 36-50$ and/or the $\beta 60-74$ peptide. Absorption experiments showed that anti- $\alpha 36-50$ and anti- $\beta 60-74$ mainly correspond to 2 non-cross reactive subfamilies of ACPA.

Conclusions Autoantibodies to $\alpha 36-50$ and $\beta 60-74$ are two distinct non-overlapping subfamilies of ACPA that together almost summarise the ACPA reactivity to citrullinated fibrinogen and to CCP2 antigens. In established RA, anti- $\beta 60-74$ autoantibodies show diagnostic indexes similar to those of anti-CCP2.

\section{A5.8 B CELL DEPLETION THERAPY IN A COHORT OF PATIENTS WITH SEROPOSITIVE AND SERONEGATIVE RHEUMATOID ARTHRITIS}

doi:10.1136/annrheumdis-2013-203219.8

ML Velloso Feijoo, R Martínez Pérez, L Mayordomo Gonzalez, JL Marenco de la Fuente. Rheumatology Unit, Valme University Hospital, Seville, Spain

Background B cells play a crucial role in the pathogenesis of rheumatoid arthritis (RA). They are responsible for the autoantibodies formation such as rheumatoid factor (RF) and anti-cyclic citrullinated peptide antibodies (anti-CCP) and the production of cytokines, act as antigen presenting cells and regulate $\mathrm{T}$ cell functions.

Rituximab (RTX), murine monoclonal antibody which selectively targets CD20-positive B-cells, has proved to be an effective and safe therapy for active RA. Initially it was used in seropositive RA, but considering the other functions of B cells, it is logical to think that it is also useful in seronegative forms. 